\title{
OUTROS CONTINGENCIAMENTOS
}

\section{Cristovam Buarque ${ }^{1}$}

Sabe-se que negar recursos financeiros ao ensino superior asfixia o país, apesar disto, as universidades estatais brasileiras têm sofrido contingenciamentos por causa ou sob desculpas de restrições fiscais. São estrangulamentos nas veias do país: porque o Conhecimento é o principal fator de produção econômica, justiça social e construção do progresso.

Em função disto, professores, alunos e servidores criaram o consenso de que nosso ensino superior não está entre os melhores do mundo por falta de recursos para financiar suas atividades. De fato, de tempos em tempos, os contingenciamentos financeiros provocam a asfixia conjuntural de nossas universidades estatais, mas uma observação mais cuidadosa permite identificar outros contingenciamentos que amarram e impedem nossa marcha à excelência.

\section{CONTINGENCIAMENTO INTELECTUAL}

O principal recurso do ensino superior são seus alunos vindos do ensino médio. É impossível ter um bom sistema universitário sem um sistema universal de educação de base com qualidade para todos. O mais grave contingenciamento de recursos que sofre a universidade está no limitado número de alunos que concluem o ensino médio e na baixa qualidade que recebem os que concluem esta etapa de sua formação. A baixa qualidade de nossa educação de base é a mais grave amarra ao bom desempenho de nosso ensino superior.

Cada pessoa deixada para trás na sua formação básica representa uma perda potencial para a universidade. Os 12 milhões de adultos analfabetos e os que não terminam o ensino médio representam um constrangimento potencial à qualidade do ensino superior, por não terem recebido a capacitação de base necessária para ingressar em um curso universitário. Os que passam no vestibular sem o preparo necessário obrigam as universidades a baixarem seus níveis de ensino e desviarem recursos do ensino superior para programas de recuperação, querendo compensar a deficiência na educação de base. São horas sacrificadas no tempo de aprendizagem e de dedicação ao ensino superior. Alguns cursos chegam ao ponto de adotar a promoção automática de seus alunos, independente das limitações que eles tenham ao longo dos cursos.

1 Professor aposentado e ex-Reitor da UNB, ex-Governador do Distrito Federal, ex-Ministro da Educação e ex-Senador da República. 
Outros chegam a oferecer diplomas para alunos que não receberam a qualificação necessária para o bom desempenho de suas profissões.

A cada ano, o ensino superior sofre o contingenciamento de recursos humanos por causa da evasão de alunos que nele ingressaram, mas sem a formação necessária para avançar, sofre também a fuga de cérebros dos muito bem formados, mas que preferem emigrar. São milhares que todos os anos saem do país em busca de melhores condições de trabalho como cientistas e professores, ou melhores condições de vida, sem a violência nas ruas, sem as doenças endêmicas, sem as incertezas econômicas e sem o constrangimento político e social, para si e sua família.

A realidade brasileira faz contingenciamento, mesmo se o governo não o fizesse.

Apesar disto, nossa comunidade acadêmica permanece alienada em relação ao contingenciamento estrutural decorrente da falta de qualidade e de universalidade na educação de base. Não denuncia que este contingenciamento estrutural é mais grave e mais permanente do que o contingenciamento financeiro conjuntural. Esquece também que a escassez de cérebros educados tem razão histórica, provocado por sucessivos governos. Nas mobilizações para impedir o suicídio nacional pelo contingenciamento de verbas, não se vê cartazes pedindo programas pela erradicação do analfabetismo ou pela federalização da educação de base, nem pelo aumento no valor do Piso Nacional do Salário do Professor da Educação de Base.

Ao dar as costas à educação de base, a comunidade universitária mostra que sua comunidade tem o mesmo sentimento elitista do conjunto da sociedade. Da mesma forma que no passado, o precário ensino superior convivia e se beneficiava da escravidão, agora tolera a desigualdade na educação de base.

\section{CONTINGENCIAMENTO DO ELITISMO SOCIAL}

A sociedade brasileira tem o sentimento de que educação de base com qualidade não é para todos os filhos de todas as classes. Ainda como herança dos 350 anos de escravidão, a sociedade brasileira sofre da deturpação moral de que a educação de base com máxima qualidade não é para todos: antes era para os brancos, agora para os ricos. Há uma total crença social e política, inclusive dentro da universidade, de que no Brasil é impossível, desnecessário e até mesmo demagógico querer e defender que a educação pública para todos seja tão boa quanto algumas escolas privadas que atendem à minoria rica. Por isto, não se aceita como progressista e ética a ideia de que pobres e ricos tenham acesso à educação de base com a mesma qualidade e disputem em condições de igualdade o ingresso 
na universidade. Considera-se mais progressista as cotas, necessárias circunstancialmente, do que a federalização da educação de base para igualar sua qualidade. Defende-se federalizar as universidades privadas, mas não se aceita federalizar a educação de base. É o elitismo que explica a insensata preferência das classes médias gastarem fortunas em escolas privadas para seus filhos, em vez de lutarem por uma escola pública gratuita para seu filho estudar ao lado dos filhos dos pobres. Este elitismo provoca o grave contingenciamento no ensino superior, pela perda de cérebros excluídos no processo de formação na base.

\section{CONTINGENCIAMENTO DEVIDO À CONCEPÇÃO DE UNIVERSIDADE}

Mesmo aqueles que se dizem contra o elitismo, não buscam abolir o privilégio de alguns terem uma boa educação de base que lhes permite o privilégio de entrar na universidade, buscam ampliar o número dos privilegiados, oferecendo compensações que favoreçam alguns dos relegados na educação de base. 0 mais progressista seria eliminar todo o privilégio, oferecendo a mesma educação de base para todos e deixando que o mérito selecione os melhores para o ensino superior. Da mesma forma que fazemos no futebol, em que a bola igualmente redonda leva à seleção apenas os melhores, sem privilegiá-los.

O desprezo dos universitários à educação de base decorre em parte da concepção de que a universidade é mais escada-social para seus alunos do que alavanca-do-progresso para o país e a humanidade. A universidade passa a ser vista e tratada como se fosse um direito individual para ascender socialmente graças ao diploma, e não um vetor do progresso pela qualidade dos serviços que seus profissionais oferecerão à sociedade, depois de formados. O ensino superior tem sido visto primordialmente como uma fábrica de diplomas e diplomados, não uma usina de conhecimento para o enriquecimento intelectual e moral. Temos movimentos e programas tipo "Universidade para Todos", mas nenhum movimento "Educação de Base com Qualidade Igual para Todos"; ainda menos um movimento para que os filhos dos pobres estudem na mesma escola dos filhos dos ricos, independente da renda e do endereço da família. Há décadas, o Movimento Negro luta, corretamente, pelas cotas para ingresso na universidade, mas raramente se manifesta pela necessidade de abolirmos o analfabetismo de adultos, mesmo que a maior parte destes seja afrodescendente. 


\section{CONTINGENCIAMENTO LINGUÍSTICO}

Nas suas origens, as universidades tinham língua comum, o latim na Europa cristã, o árabe no mundo muçulmano. Eram estas línguas francas que uniam o mundo intelectual, promovendo o intercâmbio e o avanço nas ideias. No mundo moderno, não há como ter um sistema universitário de qualidade se não for internacional, e não há como ser internacional se sua comunidade não for bilíngue. No nosso caso, falando e escrevendo bem em português e sendo fluente em inglês e, se possível, em outros idiomas. Nosso sistema universitário padece do contingenciamento linguístico, porque são raros os universitários brasileiros fluentes em inglês. Este monolinguismo amarra nossa universidade e contingencia nosso acesso às aulas, aos livros, artigos em outros idiomas, deixando nossos alunos e até muitos professores atrasados em relação ao que há de mais avançado em cada área do conhecimento.

\section{CONTINGENCIAMENTO DE IDEIAS}

O contingenciamento intelectual decorre também da recente polarização política do Brasil, que tem provocado uma aversão ao debate na universidade, provocando perda na capacidade crítica e contingenciamento de ideias, porque, mesmo com recursos financeiros, não há como fazer o pensamento avançar sem intercâmbio que exige tolerância.

Em vez de ser um mecanismo de aprimoramento para a libertação do aluno, muitos de nossos cursos de pós-graduação têm aprisionado o espírito crítico dos alunos. No lugar da liberdade criativa para o aluno-crítico, a universidade fica amarrada ao aluno-discípulo e ao professor-guru. Esta situação agrava o aprisionamento ao dificultar o fundamental diálogo e debate entre ideias diferentes. Desaparece o contraditório, base da dialética que promove o avanço do conhecimento.

Para obter o seu diploma, alunos têm de se submeter ao pensamento de seu orientador. Não é raro um aluno com uma boa ideia terminar seu tempo de estudos sem concluir a tese, ou concluí-la e obter o diploma, porque mudou de tema ou de método para submeter-se à visão do orientador. A universidade fica contingenciada por recusar o pensamento livre, criativo, original e contestador ao status-quo intelectual. A originalidade com honestidade intelectual deve ser o grande propósito de qualquer intelectual universitário. A sectarização e dominação ideológica impede estes dois propósitos; ou permite apenas honestidade, entre os ingênuos. Esta situação dos últimos anos se agravará se ficarmos submetidos por muitos anos a governos autoritários e obscurantistas. 


\section{CONTINGENCIAMENTO DE LIBERDADE}

Não há geração de conhecimento sem liberdade. Os governos autoritários buscam contingenciar a liberdade, dominar as universidades, cortando a necessária autonomia, escolhendo seus dirigentes, impondo suas ideias e seus livros; foi assim em regimes com partido único. Mesmo com discurso democrático, muitos na comunidade acadêmica recusam ouvir e debater vozes discordantes, aplicando a ideia-única, que é uma forma disfarçada de partido-único.

Nossa comunidade universitária tem ficado amarrada a políticos e partidos, o que a impede de criticar a corrupção no comportamento dos líderes que ela apoia; aceitando a corrupção nas prioridades e na ineficiência; não criticando obras sem compromisso social, nem obras paradas por erros de projetos, de execução ou por conivência com empreiteiras. A amarra partidária faz da universidade um braço político dos partidos e não a voz crítica às ideias e às estratégias de todos os partidos. Em alguns momentos, o que se vê é o aprisionamento da universidade a siglas partidárias, tendo a comunidade acadêmica como instrumento para um ou outro partido. Esta reverência a sindicatos, partidos e preconceitos intelectuais levou a comunidade acadêmica a se silenciar diante de corrupção, tanto no comportamento de políticos, quanto na definição de prioridades na política.

Entre estas corrupções, poucas são mais graves do que a corrupção das falsas narrativas que a universidade adota sem analisar, nem contestar. $\mathrm{O}$ corporativismo amarra a universidade, ao tomá-la como propriedade a serviço dos seus segmentos e não do projeto maior de construção do conhecimento para servir à humanidade. Ao sentir a universidade como sua propriedade, e não como o meio para se fazer uma nação e um mundo melhor, as universidades são contingenciadas a reduzir seus compromissos com o mérito e com a responsabilidade humanista.

É este medo da liberdade que faz as universidades federais preferirem total dependência em relação ao Estado. Recusam leis que lhes permitiriam encontrar outras fontes de financiamento e até mesmo recusam as alternativas das universidades paulistas de usarem os recursos que recebem conforme suas próprias prioridades. Temem a responsabilidade do uso livre do dinheiro que recebem.

\section{CONTINGENCIAMENTO DA INTERMITÊNCIA}

Em geral, depois de meses asfixiando a universidade, os governos anunciam que houve recuperação de receitas e que vão suspender o contingenciamento de verbas. Com a retomada destes recursos, a comunidade se acomoda, 
sem perceber que a interrupção de estudos, pesquisas e aulas tem consequências permanentes. A ideia de reposição das aulas é uma falácia. A intermitência no funcionamento regular da universidade tem consequências mais graves do que limitar o tamanho de seu orçamento, mas assegurar que os recursos assignados fluirão de maneira regular ao longo dos anos. Contar com recursos limitados, mas assegurados ao longo dos anos, é mais benéfico para o trabalho universitário do que ter generosos recursos prometidos, mas interrompidos por contingenciamentos intermitentes.

A intermitência não ocorre apenas no fluxo de recursos financeiros: a interrupção de aulas e pesquisas decorre também de outros fatores externos à universidade, e sobretudo de greves na própria universidade. Cada paralisação de atividades, mesmo com razões que a justifiquem, e mesmo com resultados positivos ao final delas, representa contingenciamento de recursos humanos. Lamentavelmente, a comunidade não faz reflexões sobre os imensos custos acadêmicos do contingenciamento de tempo devido a suas paralizações.

\section{CONTINGENCIAMENTO DO PROPÓSITO DA LUTA}

Por ser o centro da inteligência nacional, a universidade não tem o direito de ignorar os efeitos nocivos dos contingenciamentos que sofre. Mas também não tem o direito de ignorar as restrições fiscais que o país pode atravessar. Outros setores podem reivindicar mais recursos sem preocupar-se com a aritmética financeira, sem levar em conta os limites fiscais, mas a universidade, por ser o centro maior da inteligência nacional, não tem o direito de ignorar a fragilidade das finanças públicas. Quando luta por mais recursos, a universidade luta pelo futuro do país, esta é sua obrigação, mas esta luta precisa entender a realidade das restrições fiscais impostas pela irresponsabilidade fiscal, por desperdícios e pela corrupção no comportamento dos políticos e nas prioridades da política ao longo de nossa história.

Diante das necessidades de investimento para desenvolver a infraestrutura do conhecimento e, ao mesmo tempo, diante da realidade fiscal que o país atravessa, é preciso ampliar recursos financeiros para as universidades, sabendo que para isto será preciso reduzir outros gastos do setor público. Cada quantidade de cimento em obras desnecessárias, cada Real pago sob a forma de mordomias ou de propinas é um gasto que deveria servir à educação. Mas a universidade tem estado amarrada pela cultura da reivindicação sem luta: receber mais sem tirar de qualquer setor, nem mesmo dos muitos desperdícios que caracterizam os gastos públicos. Viciada na ideia de que é preciso reivindicar mais recursos sem 
lutar para tirá-los de outros gastos, a comunidade caiu no comodismo de querer mais sem criticar os roubos, mordomias ou privilégios praticados pelo Estado. A luta por mais recursos para as universidades é uma necessidade do Brasil, porque elas são o vetor do progresso, mas devem lutar por mais recursos indicando de onde eles devem sair, mantendo compromisso com a justiça social, com o fim dos desperdícios, e sem aceitar a mais estúpida das corrupções: a inflação, fazendo o contingenciamento contínuo pela perda do valor da moeda, que rouba de todos passando a ilusão de que todos ganham.

Por isto, uma das principais tarefas da universidade é usar o seu potencial intelectual e político para indicar onde os orçamentos públicos do Brasil devem reduzir gastos, privilégios, mordomias, desperdícios, ineficiências, para assim o país dispor do dinheiro necessário para financiar nossa infraestrutura intelectual, na qual está a universidade. Apenas os gastos com o estádio Mané Garrincha, símbolo do desperdício e da corrupção no Distrito Federal, teriam permitido cobrir o contingenciamento imposto em 2019 em todas as universidades do Brasil, mas a comunidade universitária assistiu esses imensos gastos sem criticar nem tentar impedir a construção deste elefante branco, e sem lutar para que estes recursos fossem orientados para as universidades e outros setores prioritários.

\section{CONTINGENCIAMENTO DO ENCLAUSURAMENTO}

Um dos mais graves contingenciamentos decorre da preferência da comunidade universitária por isolamento em relação ao mundo externo: a realidade social, as limitações de recursos, as mutações que ocorrem no mundo, as necessidades governamentais e o potencial empresarial. Há uma recusa ao conhecimento externo à academia, também ao financiamento externo ao Tesouro Público e às demandas da sociedade, dos governos e dos empresários. Ao isolar-se, a universidade perde recursos financeiros, intelectuais e motivacionais. Há uma resistência para abrir-se aos problemas e às soluções do mundo, provocando um enclausuramento que provoca asfixia tão grande quanto os cortes de verbas determinados por governos, hostis ou em crise fiscal.

Já houve casos em que universidades recusam financiamento e doação que não venham da fonte formal estatal. Embora esteja mudando, há uma recusa em aceitar convênios que, respeitando a autonomia universitária, permita uma cooperação para pesquisas de interesse do setor produtivo.

Em 2003, o Ministério da Educação propôs transferir um bilhão de reais do programa Brasil Alfabetizado para as universidades, se estas aceitassem colocar 
seus alunos como alfabetizadores de adultos, usando cada um deles algumas horas por semana, durante um semestre. Os reitores se recusaram. Um deles disse "ministro, alfabetizar adultos não é tarefa de alunos universitários". Não viu o mal do enclausuramento para o Brasil, nem a importância daquele trabalho remunerado na formação dos nossos alunos, nem na integração do ensino superior com a educação de base.

Há anos caminha pelo Congresso, sob forte oposição das universidades e de entidades de sua comunidade, um projeto de lei inspirado em ideia do cosmólogo Marcelo Gleiser, pelo qual os nossos bolsistas que voltam de mestrado e doutorado, financiados com recursos públicos, deveriam fazer uma palestra sobre suas áreas de conhecimento para alunos da educação de base.

\section{CONCLUSÃO: TODOS OS CONTINGENCIAMENTOS}

A comunidade acadêmica não tem a obrigação de lutar contra os contingenciamentos impostos pelos governos, mas tem a obrigação intelectual e moral de entender, denunciar e lutar contra todos os contingenciamentos de recursos: humanos, financeiros, políticos e culturais que amarram a universidade. 